\title{
Expectations of European's towards Family Policy and the Impact of Desired Support on Fertility Levels
}

\author{
DRAGANA AVRAMOV, Ph.D. Director of PSPC ${ }^{1}$ \\ ROBERT CLIQUET, Professor (Emeritus), Senior Advisor of PSPC
}

\begin{abstract}
On the basis of information gathered from 35,000 women and men across 14 European countries, we first look at attitudes towards fertility, children, and population dynamics. Then we analyse the expectations about the number of children people wish to have and expectations towards public policies to support them as parents. Finally, we assess the possible demographic effects of policy measures that people wish and expect to benefit from.
\end{abstract}

Most people are in favour of many traditional family policy measures. The possible effects of such policies on fertility are estimated to be modest albeit not negligible. The general conclusion is that the overall effect of the 13 traditional policy measures on increasing the number of children may be estimated at between 6 percent and 13 percent.

The general scientific insight leads us to a conclusion that a substantial and longlasting effect of policy measures to enable people to have the number of children they wish can only be expected from a comprehensive change in the labour market conditions and related enhancement of opportunities for individuals to manage their life course in innovative ways. An important asset over which people have relatively little control, up until the age at retirement, is time. Prolonged education, moreor-less long unemployment episodes, establishment in employment, postponement of parenthood, first birth in late 20s and/or experience of sub-fecundity in mid-30, excessive pressure on time in mid-life, and long years of inactivity in retirement, are features of dysfunctional economy of time in modern society. The future fertility levels may be expected to be determined by the economy of time as life's capital and not just by selected palliate measures.

$\overline{1}$ Population and Social Policy Consultants, Brussels (avramov@avramov.org; www.avramov.org) 


\section{Setting the stage}

Below replacement fertility and accelerated population ageing are the two most salient demographic phenomena that impact people's life and are relevant for a broad range of public policies at all levels of governance European, national, regional and local.

Most of Europe is characterised by fertility levels which lie more or less strongly below the level necessary for long-term generational replacement. Some of the Northern countries have levels only 20 percent below replacement, while in the largest part of Southern Europe fertility is almost 40 percent below long-term generational replacement. In most Eastern European countries fertility took a steep plunge after the beginning of the general societal transformations and passage to market economy and it is unclear what the expected stabilisation level will be (Avramov and Cliquet 2005).

At the turn of the $21^{\text {st }}$ century population ageing is the dominant demographic process in Europe. In the next fifteen years the European population will enter into a new phase of population ageing characterized not only by the increase in proportions and numbers of elderly people but also by the decrease in size of both the youth and the working age populations. Ageing will also be reflected in changes in the relative weights of broad age groups. Life expectancy increased considerably in the past decades, and health conditions, educational levels, and technological support mechanisms continuously improved and made it possible for most older people to work up to a much higher age than in the past. In contrast to the fact that people are living longer and healthier life, many countries have developed policies fostering early instead of later retirement, resulting in an ever decreasing labour force participation and occupational exclusion of younger elderly people. Biological and societal ageing have been evolving in opposite directions (Avramov and Maskova 2003).

Facts and figures on demographic trends, however, tell us little about the underpinning attitudes, preferences, expectations, and the experience of constraints to the realization of one's aspirations in life. In view to capture the population climate in Europe we set out to ask individuals what they think and how they feel about population trends and their own family choices and expectations towards their own old age.

\section{Aim of this contribution}

This contribution aims to look at preferences about childbearing and expectations about generational replacement. It analyses selected data of the internationally comparable Population Policy Acceptance Survey (PPAS) which was undertaken between 2000 and 2003 in 14 European countries: Belgium (Flanders), Czech Republic, Germany, Estonia, Italy, Cyprus, Lithuania, Hungary, Netherlands, Austria, Poland, Romania, Slovenia, and Finland. 
The 14 national PPAS datasets have been collated in an international database (IPPAS) with individual data on more than 35,000 women and men in the age range 20 to 65 (Avramov and Cliquet 2006). PPAS addressed questions covering a broad array of attitudes, preferences and expectations of citizens concerning six domains: general family related policies and attitudes; gender roles in partnership, family life and work and opinions about government policies with respect to gender related rights; reconciliation of work and family life as it relates to the combination between employment, housework, child care, and care of elderly; attitudes and experiences about having children and child-friendly policies; attitudes towards migration and immigrants; attitudes, experiences and expectations regarding intergenerational solidarity, elderly, one's own old age and population ageing (Höhn, Avramov and Kotowska 2007). ${ }^{2}$

\section{Attitudes towards fertility, children and population dynamics in Europe}

PPAS included several subjects which throw some light on attitudes of Europeans on the future of Europe's population: opinion on future population growth; opinion on the declining proportion of young people in 50 years; opinion on the increasing number of couples who decide to remain childless; opinion on the declining number of births; opinion on the duty of citizens towards society to have children.

When we pool and weigh the data in view to look at the numbers of respondents sharing views and expectations irrespective of their country of origin, we see that a majority of Europeans consider a population decline as an unfavourable or undesirable perspective. The pooled and weighted data for the respondents below age 50 show that:

- 7 out of every 10 respondents considered the expected declining proportion of young people in the next 50 years as bad or very bad;

- 3 out of every 4 were of the view that the declining number of births is bad or very bad;

- 6 out of every 10 esteemed the increasing childlessness of couples as bad or very bad;

- 4 out of every 10 preferred the population to increase and an equal number wanted it to remain the same; only 1 out of 10 people preferred a decrease;

- respondents were divided regarding the question if it is the duty of citizens towards society to have children: 4 out of 10 agreed or strongly agreed that it is a duty, and 4 out of 10 disagreed or strongly disagreed, while 2 out of 10 did not have an opinion on this statement.

2 The international comparative study 'Population Policy Acceptance Study - The Viewpoint of Citizens and Policy Actors Regarding the Management of Population Related Change' - was financed by the European Commission within its $5^{\text {th }}$ Framework Programme in the period December 2002 - November 2005 (Contract HPSE-CT-2002-00153, Acronym 'DIALOG'). 
The national socio-cultural context, however, continues to be of pivotal importance for patterning of opinions and expectations. Indeed, the most striking variation is in the cross-country differences in opinions on future fertility and population development. For instance, the percent who considered the declining proportion of young people in the next 50 years to be bad or very bad varied between 5 out of 10 respondents in the Netherlands, at the lower end of the scale, and 9 out of every 10 respondents in Eastern Germany, at the upper end of the scale. An even stronger variation was found when only the "very bad" opinion is considered: percentages ranged from 5 to 47 percent. The Low Countries showed the smallest percentages, most Eastern European countries and Cyprus showed the highest proportions of people who consider the expected decline in youth to be very bad. These cross-country differences in opinion are strongly related to the differences in TFR (Figure 1).

A strong between-country variation was also found to the question about the duty of citizens towards society to have children. In the Netherlands and Belgium less than 10 percent consider having children as a duty, whereas the proportion in the Czech Republic is as high as 60 percent.

Figure 1. Relation between the proportion of the respondents who consider the declining proportion of young people in 50 years as 'very bad' and the Total Fertility Rate (TFR) in the PPAS countries

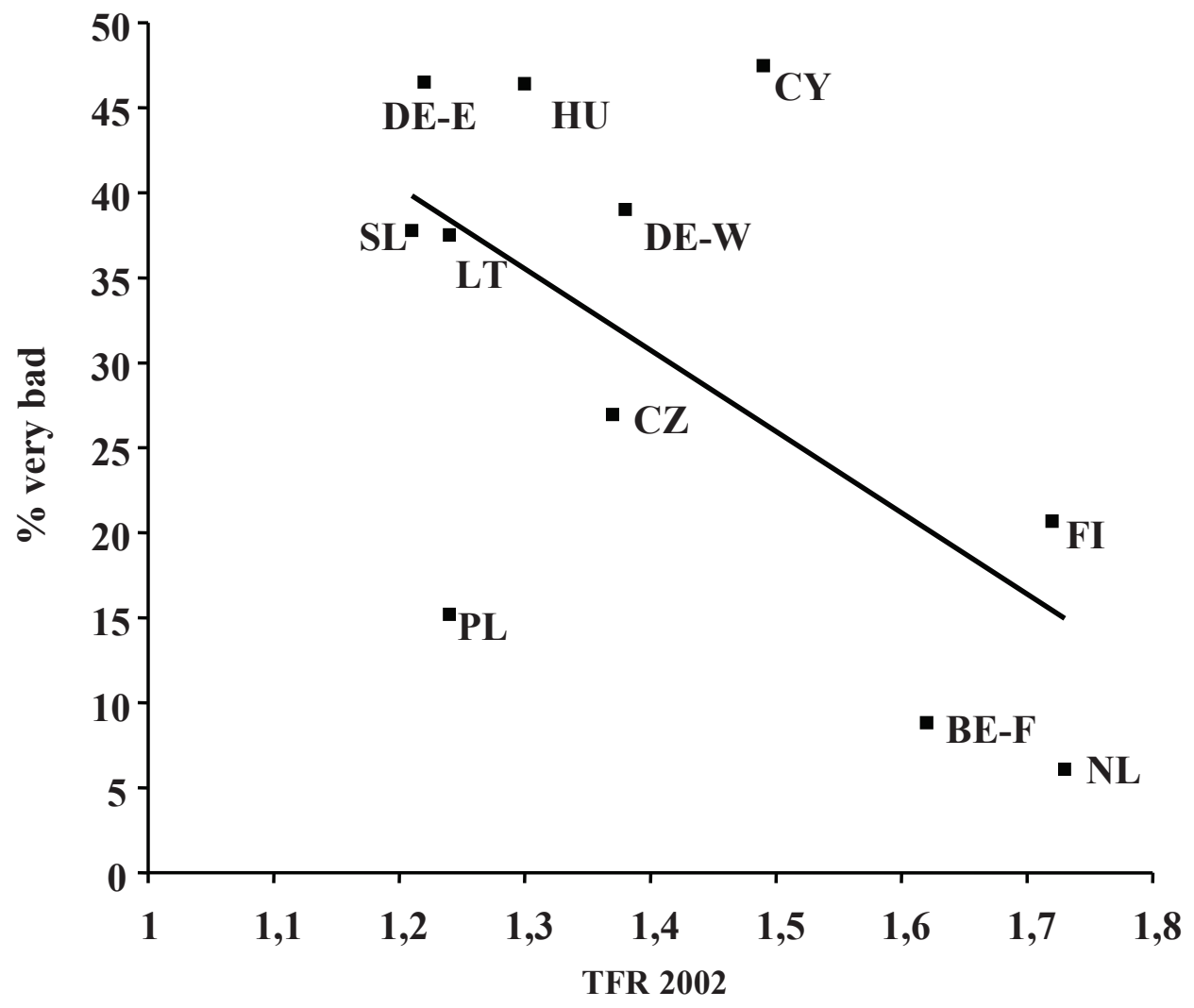

Source: IPPAS database (Avramov and Cliquet 2006) 
For all of those opinions, there were some salient variations according to particular characteristics of the respondents. For instance, younger people held less negative views about the predicted trends than older generations in all the countries.

\section{Personal expectations concerning the number of children}

Our study shows that in the 14 countries people would like to have more children than what the current total fertility rate in their country shows. In Germany, Belgium (Flanders), Finland, and the Netherlands the total number of children respondents expect to have over their life course is slightly higher than the present total fertility rate. In all the Eastern European countries, and in Italy, Cyprus and Austria the expected number lies considerably above the present fertility levels in the country (Figure 2). In Estonia, remarkably, the total fertility rate stands at 1.37 children per woman, and is thus 35 percent below replacement level. If people actually had the number of children they wish today, the total fertility rate would be comfortably above the replacement level.

PPAS included information on the number of children, the desire for another child, the additionally expected number of children and the reasons for not wanting another child. On the basis of these variables we calculated the demographic impact of expectations and constraints to the realization of expectations.

The number of children increases with age and the additionally expected number of children obviously decreases with age (Figure 3). The sum of both shows for the pooled PPAS sample almost no variation according to age. However, this results from slightly opposite trends among women and men (Figure 4). Obviously, some substantial differences can be found according to country. In general, there is a strong correlation between the actual number of children and the total expected number of children $(\mathrm{r}=0.6)$. This positive association persists also cross-country wise (Figure 5), implying that countries with earlier births may expect higher final descendence, and vice versa. However, in some cases, e.g. the Netherlands, Estonia and Cyprus, there are doubts about the feasibility of the full realization of the high expectations.

Interrelating TFR and total expected number of children per country illustrates the striking phenomenon of childbirth postponement in Eastern Europe as a result of the recent societal transition, and the intention of fertility recuperation in that part of Europe (see again Figure 2).

In the PPAS samples female employment was still negatively related to fertility: fulltime employed women have and expect fewer children than part-time employed or 
Figure 2. The relation between the Total Fertility Rate and the total number of children respondents expect to have during their life course, by country

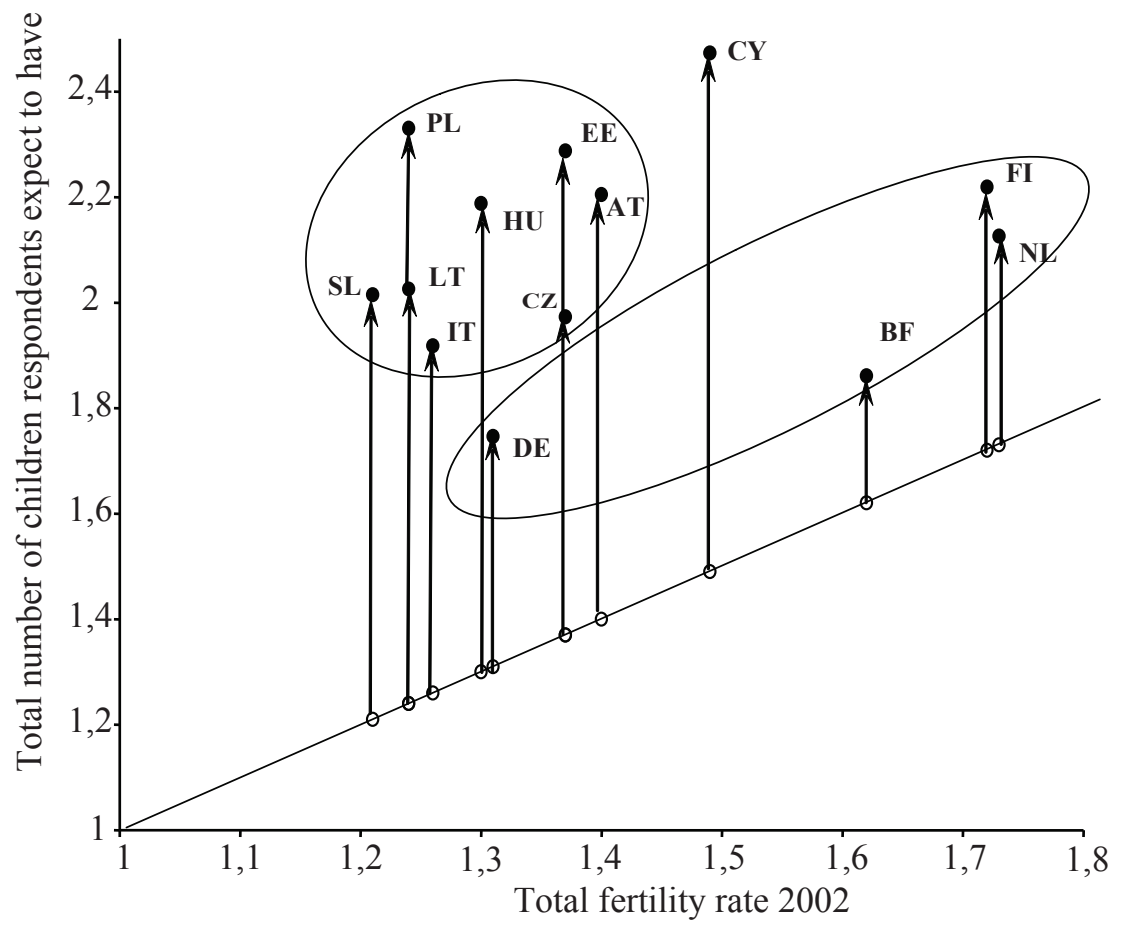

Source: IPPAS database (Avramov and Cliquet 2006)

Figure 3. Number of children, additional expected number of children and total expected number of children, adjusted for life course obstacles, by age group (pooled and weighted data)

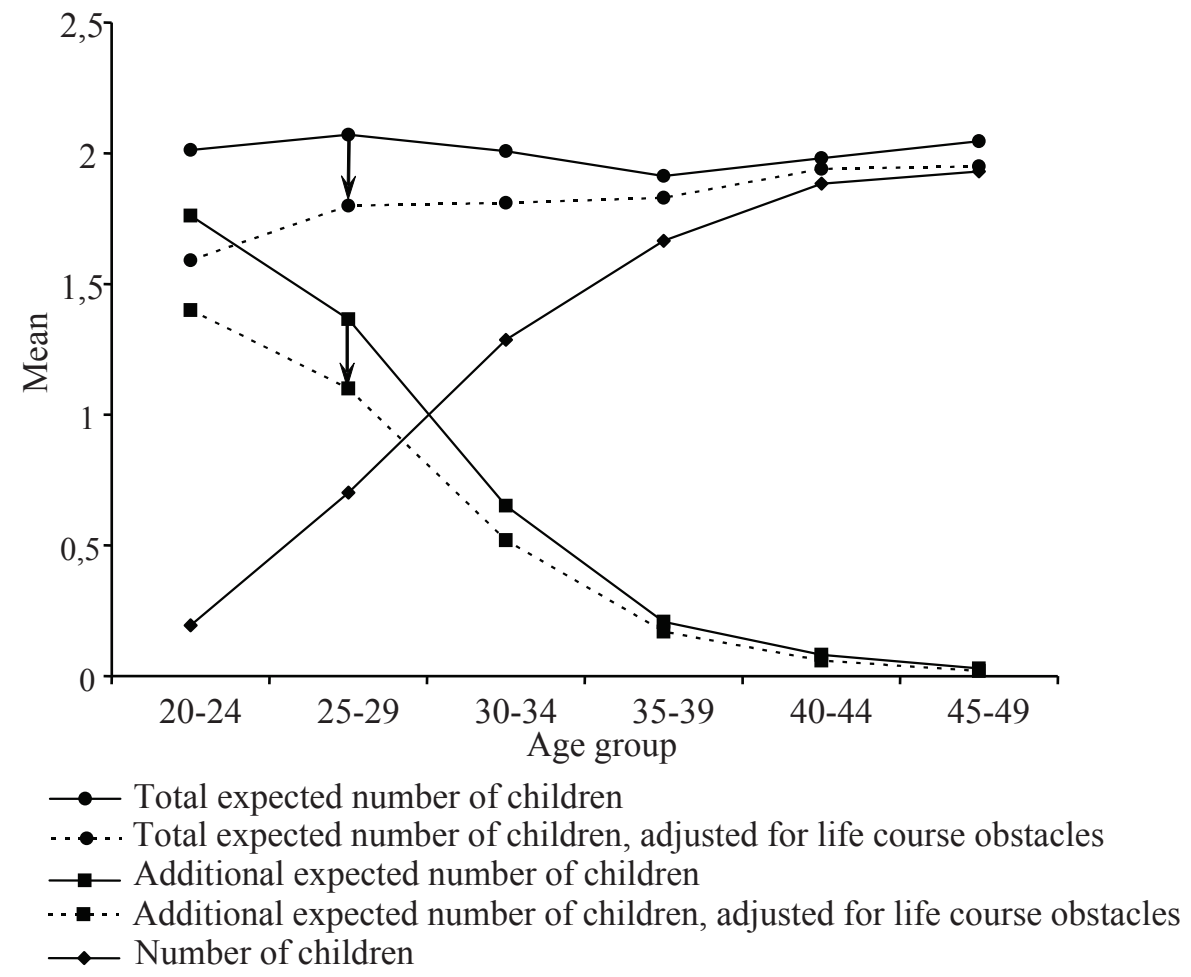

Source: IPPAS database (Avramov and Cliquet 2006) 
jobless women. Among female respondents below age 50, the total expected number of children amounts respectively to 1.79, 2.08 and 2.19. As far as concerns the ideal combination between work and having children, 42 percent of women below the age of 50 prefer part-time work and children; 27 percent opt for a full-time job and children; 23 percent do not want to work when children are present or young; only 7 percent wants a (part- or full-time) job without children. In most countries, a higher expected fertility is associated with a preferred part-time job.

With respect to future fertility we observe that, on average, men aged 20 to 35 expect to have over their life course maximum 1.5 children (Figure 4). Women in the same age group expect to have on average 1.7 children. This leads us to a conclusion that better understanding of the male perception of parenthood and enhancement of men's wish for children might require more prominent policy attention.

\section{Individual expectations and barriers}

In view to assess the possible demographic impact of current expectations it is necessary to look at both perceived and latent obstacles to people's wishes. This means that the total expected number of children resulting from the combination of the already realised fertility and the expressed intention to have additional children in PPAS have to be corrected for life course events that result in deficit and excess fertility, i.e. realised fertility that lies below or above the level intended.

Figure 4. Maximum expected final descendence, by sex

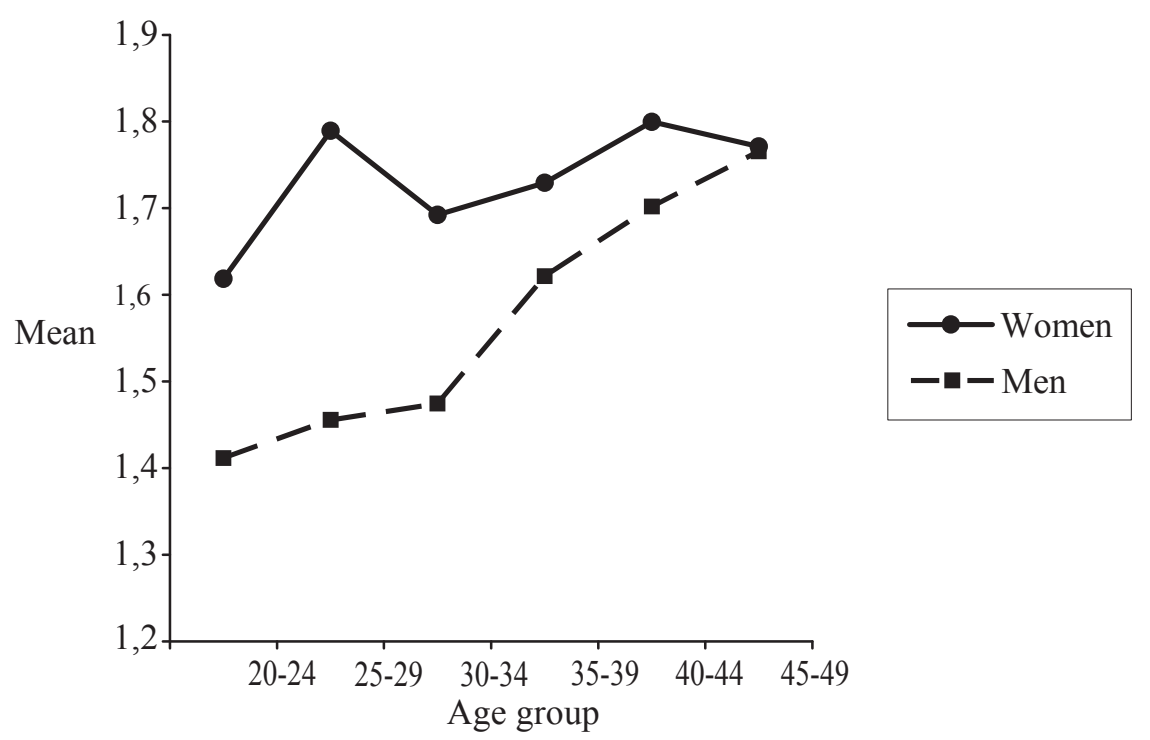

Pooled and weighted data for: Belgium (Flanders), Czech Republic, Germany, Estonia Italy, Cyprus, Lithuania, Hungary, Netherlands, Austria, Poland, Slovenia, and Finland.

Source: IPPAS database (Avramov and Cliquet 2006) 
Figure 5. The relation between the number of children and the total expected number of children, by country

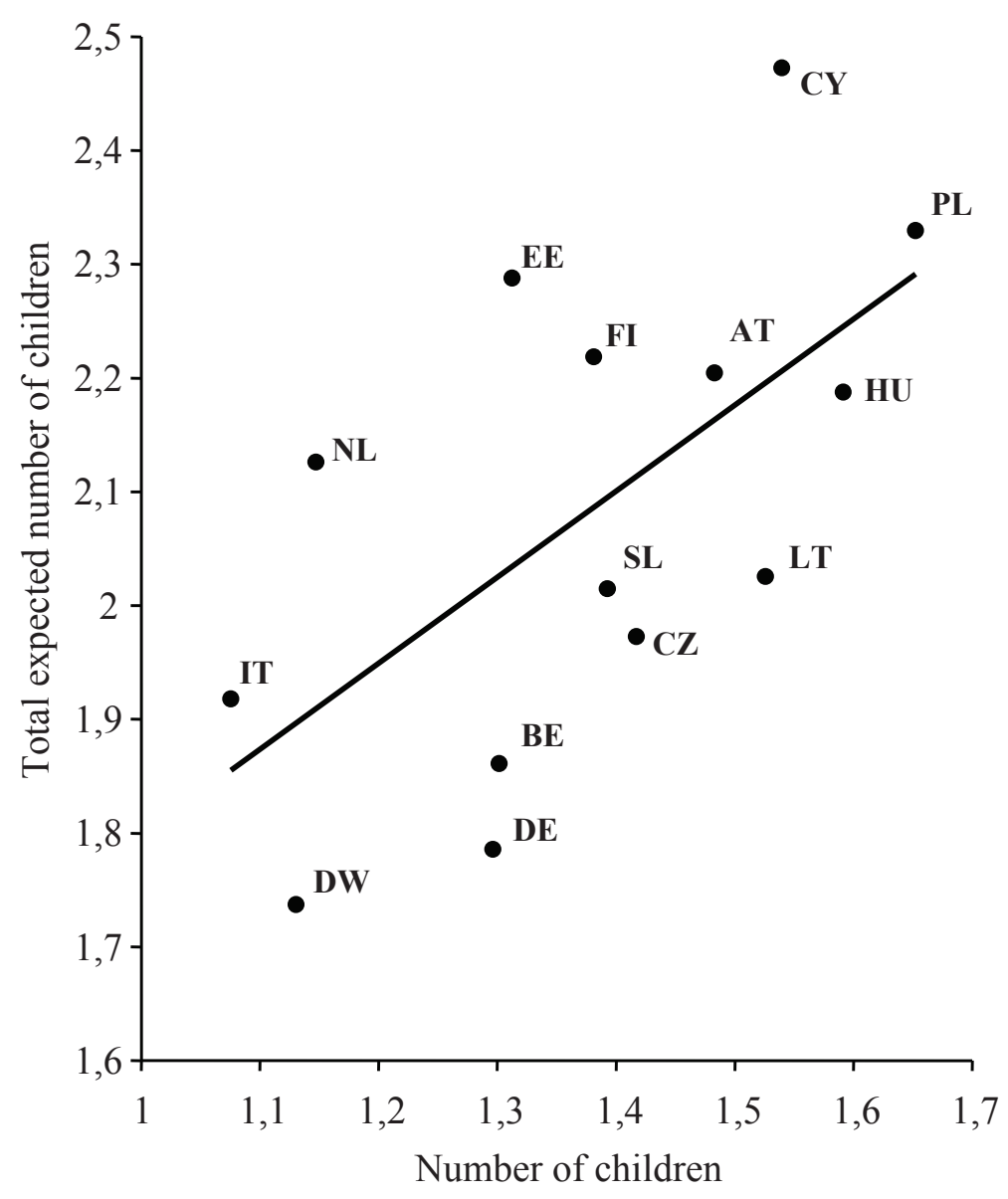

Source: IPPAS database (Avramov and Cliquet 2006)

Fertility surveys in the past decades have shown that excess fertility has become a minor problem thanks to the generalised use of modern contraceptives and the availability of induced abortion facilities. Deficit fertility, however, is a major problem.

Our calculation which takes into account deficit fertility in evaluating and correcting expressed fertility intentions is based on two major sources of information: the results of earlier investigations on reproductive behaviour and research about recent societal trends with respect to family life.

For the purpose of this analysis we have first taken data from the two most recent Flemish fertility surveys (1982 and 1991). Here, information was gathered on the number of women who had fewer children than desired and the reasons for this deficit fertility. One out of five women aged 35 to 39 have fewer children than they wish (Table 1). Applying the Flemish correction factor of 20 percent to the pooled PPAS data, the total expected number of children for the youngest age group (20-24) eventually may be expected to decrease from 2.00 to 1.75 children (Figure 3 ). 
Table 1. Deficit and excess fertility in Flanders, by age group (Fertility and Family Survey 1991)

\begin{tabular}{lcccccr}
\hline \multirow{2}{*}{ Realised and desired number of children } & \multicolumn{4}{c}{ Age group } & \multirow{2}{*}{ Total } \\
\hline Realised fertility is smaller than desired fertility & $20-24$ & $25-29$ & $30-34$ & $35-39$ & \\
Realised fertility equals desired fertility & 25 & 29 & 56 & 72 & 48 \\
Realised fertility is higher than desired fertility & 0 & 1 & 3 & 7 & 3 \\
$\mathrm{~N}(=100 \%)$ & 847 & 1,237 & 1,273 & 1,354 & 4,711 \\
\hline
\end{tabular}

Source: Population and Family Study Centre (CBGS), Brussels; Cliquet and Callens 1993

The Flemish surveys also showed that, contrary to what is often thought, the major reasons for deficit fertility in a western country are not so much of an economic nature, but have mainly to do with socio-biological factors (in particular sub-fecundity at higher ages), relational problems (e.g. no partner, divorce), and socio-psychological factors (various lifestyle options which result in low fertility) (Table 2).

We are aware that socio-economic factors might have a greater weight in other parts of Europe, notably in Eastern Europe where the recent socio-economic transitions created increased levels of existential insecurities. These in turn have contributed to a considerable postponement of births and a salient decrease in period fertility rates. Therefore, the impact of economic factors is probably higher and a correction factor of 20 percent may be too low.

Table 2. Reason for deficit fertility in Flanders, by age group (Fertility and Family Survey, 1991)

\begin{tabular}{lrrrrr}
\hline \multirow{2}{*}{ Reason for deficit fertility } & \multicolumn{5}{c}{ Age group } \\
& $20-24$ & $25-29$ & $30-34$ & $35-39$ & Total \\
\hline Still in the process of family formation & 64 & 65 & 48 & 29 & 56 \\
Material living conditions & 3 & 5 & 5 & 5 & 4 \\
Socio-biological factors & 6 & 8 & 15 & 30 & 12 \\
Relational factors** & 21 & 16 & 17 & 25 & 19 \\
Other & 6 & 6 & 15 & 11 & 9 \\
N (=100\%) & 573 & 803 & 507 & 288 & 2,171 \\
\hline
\end{tabular}

* age, health, subfecundity, genetic impairment

${ }^{* *}$ no (more) partner, quality of relationship, low fertility desire of partner

Source: Population and Family Study Centre (CBGS), Brussels; Cliquet and Callens 1993

The major recent societal trends which can be expected to have a depressing effect on reproductive behaviour are increasing female employment, the increase of alternative living arrangements, the increase of marital disruption, and increasing secularisation (Table 3). To the extent that these trends tend to persist or even increase, it may be expected that, in the present socio-economic context, fertility remains low. 
Table 3. Total expected number of children according to various sociological characteristics of respondents $<50$ years of age in PPAS (pooled and weighted data)

\begin{tabular}{llc}
\hline Sociological characteristic & Category & $\begin{array}{c}\text { Total expected number } \\
\text { of children }\end{array}$ \\
\hline Female employment & Full-time employment & 1.81 \\
& Part-time employment & 2.11 \\
& No job & 2.24 \\
\hline Living arrangement & 'Living-apart-together' sensu stricto* & 1.50 \\
& Non-marital cohabitation & 1.80 \\
& Marital cohabitation & 2.14 \\
\hline Marital status & Married & 2.29 \\
& Separated & 1.93 \\
& Divorced & 1.90 \\
\hline Religiosity & Church going - religion very important & 2.42 \\
& Church going - religion important & 2.10 \\
& Non-church going - religion important & 2.01 \\
& Church going - religion not important & 1.84 \\
& Church-going - religion not relevant at all & 1.66 \\
& Non-church going - religion not important & 1.66 \\
& Non-church going - religion not relevant at all & 1.49 \\
\hline
\end{tabular}

* 'Living-apart-together' sensu stricto: couples having separate households, but not living with their parents.

Source: IPPAS database (Avramov and Cliquet 2006)

\section{Expectations towards family policies}

PPAS gathered information on preferences for 13 traditional existing or desired family policy measures. We looked at support for improving parental leave; lower income tax for families with dependent children; better day-care for children below 3; better daycare for children above 3; income-dependent child allowance; allowance at childbirth; allowance for care-taking parents; substantial rise in child allowance; childcare for school-going children; flexible working hours; more opportunities for part-time work; substantial decrease in costs for education; better housing for families with children.

Eight out of every 10 respondents (women and men below the age of 50) are strongly in favour or in favour of each of the above measures.

Some differences in preferences for specific measures are observed according to various social-demographic characteristics of the respondents. For example, large families are more in favour of financial support measures, whereas smaller families are more favourable to measures which facilitate the combination of work and family life. 
When we look at which of the 13 proposed policy measures was favoured by the highest percentage of people in each country we observe quite a variation. Working conditions (more and better part time work or flexible working hours) are preferred by the highest proportion of respondents in Austria, Belgium, Netherlands, Finland, Germany and Italy. Various forms of child allowance in the Czech Republic, Lithuania and Poland whereas lower taxes for families with dependent children have the highest support in Romania and Cyprus. Better housing in Hungary and Slovenia, and lower cost of education in Estonia were supported by the highest shares of nationals.

\section{Possible effects of policies on fertility}

In the PPAS we asked people to assess the possible impact on their fertility behaviour if the desired family policy measures would be implemented. We looked at the impact of policy in terms of: having the number of children the respondent wants, enabling the respondent to have the next child sooner, reconsidering to have a(nother) child, and probably deciding to have a(nother) child. In addition to these four variables, a composite variable, cumulating the positive answers on the consequence questions, has been constructed (Cronbach's alpha $=0.74$ ).

In order to analyse the possible effects of the family policy measures on fertility, not only the relations between measures and possible consequences, but also the relations between the measures and the total expected number of children can be investigated.

In general, positive relations are found between the individual policy measures considered and the possible consequences of the implementation of desired family policy measures on future childbirth. The strength of the relation, however, varies according to the measure considered.

The correlation between the family policy measures and the possible consequences of the implementation of desired family policy measures on future fertility, based on the relation between the two composite variables, is positive $(\mathrm{r}=0.30)$. The correlation between the composite variable on policy measures and the total expected number of children is low $(r=0.08)$. A somewhat stronger association is found between the composite variable on the consequences of the implementation of desired family policy measures and the additionally expected number of children $(r=0.24)$, but the correlation with the total expected number of children is much lower $(r=0.09)$.

How much might the 13 family policy measures boost fertility? On the basis of the number of respondents who originally didn't know whether they would get a(nother) child and those who initially declared not to want a(nother) child, but who after considering the policy measures stated that they would probably decide to have a(nother) 
Table 4. Possible effects of family policy measures on the number of children among respondents $<50$ years of age in PPAS

\begin{tabular}{|c|c|c|c|}
\hline & Item & \multicolumn{2}{|c|}{ Mean number of children } \\
\hline 1 & Number of children & \multicolumn{2}{|c|}{1.20} \\
\hline 2 & Additional expected number of children & \multicolumn{2}{|c|}{0.74} \\
\hline 3 & Total expected number of children $(1+2)$ & \multicolumn{2}{|c|}{$1.2+0.74=1.94$} \\
\hline 4 & $\begin{array}{l}\text { Minimal effect of policy measures } \\
\text { (only respondents who don't know whether to get } \\
\text { a(nother) child or want no more children, but who } \\
\text { would probably decide to have a(nother) child at } \\
\text { implementation of desired policy measures) }\end{array}$ & \multicolumn{2}{|c|}{$(2556 / 14074) 0.739=0.13$} \\
\hline \multirow[t]{2}{*}{5} & $\begin{array}{l}\text { Additional effect of policy measures (all respondents } \\
\text { who would probably decide to have a(nother) child } \\
\text { at implementation of desired policy measures) }\end{array}$ & \multicolumn{2}{|c|}{$(2986 / 14074) 0.739=0.16$} \\
\hline & & $\begin{array}{l}\text { Minimal effect of } \\
\text { policy measures }\end{array}$ & $\begin{array}{l}\text { Maximal effect of } \\
\text { policy measures }\end{array}$ \\
\hline 6 & Total expected number of children + policy effect & $1.94+0.13=2.07$ & $\begin{aligned} 1.94 & +0.13+0.16 \\
& =2.23\end{aligned}$ \\
\hline \multirow[t]{2}{*}{7} & $\begin{array}{l}\text { Total expected number of children + policy effect, } \\
\text { corrected for life course obstacles }(-20 \%)\end{array}$ & $\begin{array}{c}1.2+\{0.74-(0.74 x \\
0.2)\}+\{0.13-(0.13 x \\
0.2)\}=1.89\end{array}$ & $\begin{array}{c}1.2+\{0.74-(0.74 x \\
0.2)\}+\{0.13-(0.13 x \\
0.2)\}+\{0.16-(0.16 x \\
0.2)\}=2.02\end{array}$ \\
\hline & & \multicolumn{2}{|c|}{$\%$ policy effect } \\
\hline 8 & $\%$ policy effect on total expected number of children & $\begin{array}{c}(2.07-1.94) / 1.94 x \\
100=6.7 \%\end{array}$ & $\begin{array}{c}(2.23-1.94) / 1.94 x \\
100=14.9 \%\end{array}$ \\
\hline 9 & $\begin{array}{l}\% \text { policy effect corrected for deficit fertility estimated } \\
\text { at } 20 \%\end{array}$ & $\begin{array}{c}(1.89-1.79) / 1.79 x \\
100=6.0 \%\end{array}$ & $\begin{array}{c}(2.02-1.79) / 1.79 x \\
100=13.0 \%\end{array}$ \\
\hline
\end{tabular}

child if the desired family policy measures are implemented, we calculated the effect of policy. The estimated increase of the number of children is some 7 percent. This is, however, a minimal increase. It may underestimate the real potential for policy impact. Namely, also the respondents who said that they intend to have a(nother) child may decide to have more children than initially intended if the desired family policy measures were set in place. By considering the two groups together we estimated that the increase in the number of children would be some 15 percent.

Whereas desired measures may enhance desire for children the demographic impact needs to be assessed taking into consideration also obstacles people do not clearly perceive or acknowledge. When we apply the survey-based Belgian (Flemish) correction factor for deficit fertility due to life-course obstacles, to the pooled PPAS data, the estimated minimal and maximal effects of desired family policy measures decrease from 7 to 6 percent and from 15 to 13 percent respectively. Table 4 summarises the calculation procedure. The possible decrease, however, varies quite substantially according to country, as can be seen in figure 6 . 
Figure 6. Positive effect on fertility of desired policies, taking into account expectations and possible life-course obstacles, by country

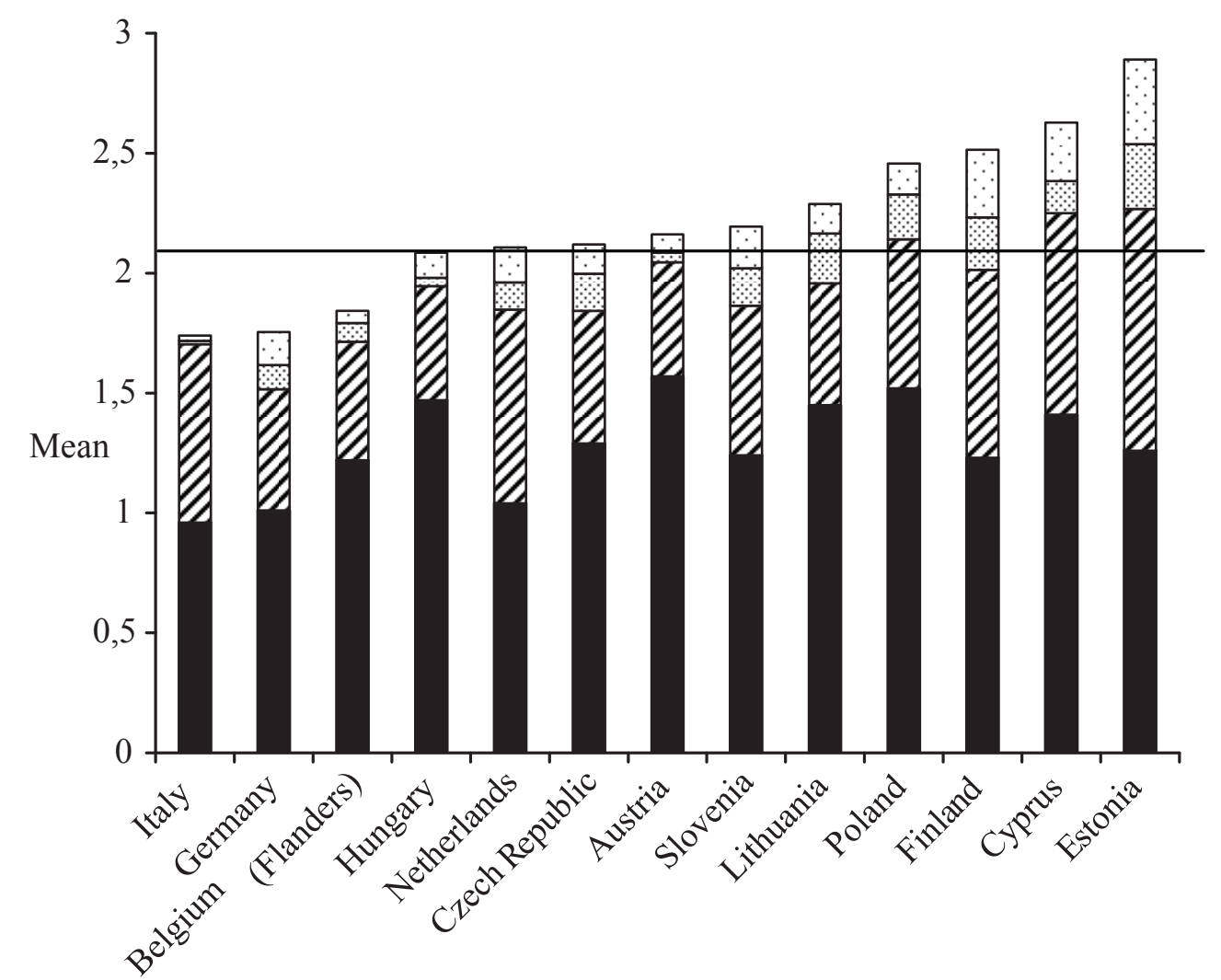

$\square$ Additional number of children respondents might have if desired policy measures are implemented O. Number of children respondents might have if desired policy measures are implemented

$\checkmark$ Number of children respondents intend to have

Number of children respondents already have

Source: IPPAS database (Avramov and Cliquet 2006)

\section{Conclusions about possible effect of policy measures on fertility}

The general conclusion is that the overall effect of the 13 proposed policy measures on increasing the number of children may be estimated at between 6 percent and 13 percent.The family policy measures considered in PPAS may have a slight positive effect on completed fertility.

The cautious analysis of PPAS data does, however, indicate that if a comprehensive basket of measures were introduced that combines enhancement of family-friendly employment with family-friendly support services and direct and indirect financial support to parents of dependent children, fertility levels would go up close to or even above replacement level in the majority of countries. This could be the case in Estonia at the higher end of the scale, Cyprus, Finland, Poland, Lithuania, Slovenia, Austria, 
Czech Republic, the Netherlands, and Hungary. These countries would be much better placed to deal with negative consequences of population ageing. However, to bring fertility close to replacement in Germany, Italy and Belgium, the population may expect much more than the 13 measures studied under the DIALOG project.

The general scientific insight leads us to a conclusion that a substantial and long-lasting effect of policy measures to enable people to have the number of children they wish can only be expected from a comprehensive change in the labour market conditions and related enhancement of opportunities for individuals to manage their life course in innovative ways. An important asset over which people have relatively little control, up until the age at retirement, is time. Prolonged education, more-or-less long unemployment episodes, establishment in employment, postponement of parenthood, first birth in late 20s and/or experience of sub-fecundity in mid-30, excessive pressure on time in mid-life, and long years of inactivity in retirement, are features of dysfunctional economy of time in modern society. The future fertility levels may be expected to be determined by the economy of time as life's capital and not just by selected palliate measures, even when they come in a basket (Avramov and Cliquet, 2003; 2005).

Family-friendly labour market conditions, opportunity to manage time better in a life course perspective, and the sense of security that stems from the knowledge that social support is available over the entire life-course and not just during the early childrearing years may be the key to future fertility levels.

\section{References}

Avramov, D. and M. Maskova. 2003. Active Ageing in Europe. Strasbourg: Council of Europe Publishing.

Avramov, D. and R. Cliquet. 2003. Economy of Time and Population Policy: Rethinking the 20th Century Life Course Paradigm in the Light of Below-replacement Fertility. Zeitschrift für Bevölkerungswissenschaft, 28 (2-4): 905-938.

Avramov, D. and R. Cliquet. 2005. Integrated Policies on Gender Relations, Ageing and Migration in Europe: Lessons from the Network for Integrated European Population Studies (NIEPS). CBGS Publications. Antwerpen-Apeldoorn: Garant.

Avramov, D. and R. Cliquet. 2006. Manual, Questionnaire, Codebook and Database of the International Population Policy Acceptance Study (IPPAS). BiB-Materialien. Wiesbaden: Bundesinstitut für Bevölkerungsforschung.

Cliquet, R. L. and M. Callens (eds.). 1993. Gezinsvorming in Vlaanderen: hoe en wanneer? Resultaten van de Enquête Gezinsontwikkeling 1991 (NEGO V). CBGS-Monografie, 1993/1. Brussel: Centrum voor Bevolkings- en Gezinsstudien, Ministerie van de Vlaamse Gemeenschap.

Höhn, C., D. Avramov, I. Kotowska (eds.). 2007. People, Population Change and Policies. Lessons from the Population Policy Acceptance Study. European Studies of Population. Springer Publishing. In press. 